\title{
La pensión como derecho fundamental en el sistema de seguridad social colombiano
}

\section{The pension as a fundamental right in the Colombian social security system}

\author{
ALCIRA MUÑOZ OSORIO \\ Abogada. Especialista en Derecho Administrativo, Especialista en Derecho Laboral y Seguridad Social, \\ Maestrante en Derecho Administrativo. Docente del programa de Derecho. \\ alcysamunoz@hotmail.com
}

GIANNINA ESGUERRA MUÑOZ

Abogada especialista en derecho laboral y seguridad social, funcionaria de la rama judicial gianninaesguerramunoz@gmail.com

Recibido: el 5 de Octubre de 2012

Aceptado: el 19 de Noviembre de 2012

\section{RESUMEN}

En este artículo de reflexión se hace un análisis del carácter fundamental de la pensión, a partir de su condición de integrante principal de la Seguridad Social. Para lograr este propósito primero se revisaron los artículos de la Constitución Política que le dan el soporte legal a la Seguridad Social, seguidamente se hizo una reseña histórica de la evolución de las pensiones en Colombia. Se hizo una revisión de la Jurisprudencia de la Corte Constitucional, relativa al tema tratado y de la crisis del Sistema Pensional Colombiano. Con base a todo lo mencionados se llegó a la conclusión que da respuesta al interrogante planteado.

Palabras claves: Derecho fundamental, seguridad social, pensión, estado social de derecho, crisis del Sistema Pensional Colombiano, Constitución Politica.

\begin{abstract}
This reflection paper aims to analyse the fundamental nature of the pension, as an integral part of colombian Social Security system. To achieve this purpose, we first reviewed the articles of the Constitution that give legal support to Social Security. Then we present a historical overview of the evolution of pensions in Colombia. We performed a review of the jurisprudence of the Constitutional Court concerning the subject matter and the crisis of the Colombian pension system. Key words: Fundamental rights, social security, pension, social state of law, Colombian Pension System crisis, Political Constitution
\end{abstract}

\section{Introducción}

El propósito trazado con este articulo de reflexión ha sido el de intentar una aproximación a una respuesta a la gran inquietud que existe en muchos colombianos acerca de si se puede, o no, considerar a la pensión, en su condición de integrante de la Seguridad Social, como un Derecho Fundamental. Para tal fin se revisaron los requisitos que deben reunir tales derechos. Se analizaron: el artículo 48 de la Constitución Política (C. P.) que establece la Seguri- 
dad Social como un servicio público de carácter obligatorio e irrenunciable; el Acto legislativo 01 de 2005 que se adiciona y complementa el anterior; y los artículos 44, 46, 47, 49 y 50 de la Constitución Política relativos a la Seguridad Social. Se hizo una revisión exhaustiva de los antecedentes históricos de las pensiones en el país, pasando por: la Constitución Política Colombiana de 1886; la Ley 50 de 1886; la Ley 39 de 1903; la Ley 29 de 1905; la Ley 29 de 1912; la Ley 57 de 1915; la Ley 37 de 1921; la Ley 40 de 1922; la Ley 86 de 1923; la Ley 37 de 1925; la Ley 15 de 1925 ; la Ley 116 de 1926; la Ley 102 de 1927 ; la Ley 114 de 1934 ; la Ley 10 de 1934 ; el Decreto 2350 de 1944; la Ley 6ta de 1945; el Decreto ley 1600 de 1945; Ley 90 de 1946; Ley 4ta de 1966; Decreto 3135 de 1968 y su reglamentario 1849 de 1969; Decreto ley 3135 de 1985; la Lley 33 de 1985; Acuerdo 049 de 1990; la Ley 100 de 1993 y las Leyes 797 y 860 de 2003. Igualmente se realizó un análisis sobre: la obligatoriedad de afiliación al sistema pensional colombiano; la jurisprudencia constitucional que garantiza la protección a la seguridad social y sobre la crisis en el sistema pensional colombiano. Producto de todo lo anterior, se llegó a una conclusión que trató de dar respuesta al interrogante planteado ¿Es la pensión un derecho fundamental?

\section{¿Es la pensión un derecho fundamental?}

Antes de determinar si la pensión es un derecho fundamental, primero es necesario determinar el carácter fundamental de la seguridad social. En tal sentido, es pertinente referirse al significado de derecho fundamental, en Colombia, son derechos fundamentales aquellos derechos que son inherentes al ser humano, y deben cumplir por lo menos alguna de las condiciones que se mencionan a continuación.

1. Estar reconocido expresamente como tal por la propia Constitución.

2. Tener como sujeto a la persona humana en cuanto a titular de bienes primarios cuyo origen está en la esencia misma del hombre.

3. Estar enunciado entre los derechos de aplicación inmediata.

4. Estar enunciado en los instrumentos internacionales que desarrollan las proclamaciones de la Declaración Universal de Derechos Humanos.

5. Estar protegido a través de una garantía especial en cuya virtud las reformas constitucionales que lo afecten puedan someterse eventualmente, por iniciativa popular, al referendo previsto en el artículo 377 de la Constitución.

6. Poseer un núcleo esencial que ni siquiera sea legítimo alterar cuando se decrete el estado de excepción en caso de guerra exterior o de conmoción interior.
Además, según la Corte Constitucional, el carácter fundamental de un derecho "no se puede determinar sino en cada caso concreto, atendiendo tanto la voluntad expresa del constituyente como la conexidad o relación que en dicho caso tenga el derecho con otros derechos indubitablemente fundamentales y/o con los principios y valores que informan toda la constitución (Defensoría del pueblo, 2001).

La Organización Internacional del Trabajo ha definido en su documento "Administración de la Seguridad Social" que " a protección que la sociedad proporciona a sus miembros, mediante una serie de medidas públicas, contra las privaciones económicas y sociales que, de no ser así, ocasionarían la desaparición o una fuerte reducción de los ingresos por causada de una enfermedad, maternidad, accidente de trabajo, enfermedad laboral, desempleo, invalidez, vejez y muerte; y también la protección en forma de asistencia médica y de ayuda a las familias con hijos" (Díaz Sanabria, 2012).

El sentido de seguridad Social es la protección del individuo para poder hacerle frente a las contingencias que se le puedan presentar antes durante y después de su vida laboral se han establecido cinco grupos de riesgos ellos son: riesgos ECM, IVM, ATEP, D, Asignaciones Familiares, para cubrir estos se el sistema brinda unas prestaciones que son de dos tipos, asistenciales y económicas, con el fin de contrarrestar el aumento de gastos que se presenta con una situación de enfermedad, invalidez, desempleo, vejez etc. Cualquiera de estos riesgos puede afectar las condiciones de vida de las personas en forma temporal, definitiva, total, parcial.

\section{La Constitución Política de Colombia frente a la seguridad social}

La Constitución colombiana de 1886, en materia de seguridad social, no realizo aportes significativos a esta área del derecho laboral y seguridad social, la Carta Política de 1991, fue más generosa en esta materia, se elevo a rango constitucional el derecho a la seguridad social.

Los artículos siguientes regulan la seguridad social en el país.

...Articulo 48 Constitución Nacional: La Seguridad Social es un servicio público de carácter obligatorio que se prestará bajo la dirección, coordinación y control del Estado, en sujeción a los principios de eficiencia, universalidad y solidaridad, en los términos que establezca la Ley.

Se garantiza a todos los habitantes el derecho irrenunciable a la Seguridad Social. El Estado, con la 
participación de los particulares, ampliará progresivamente la cobertura de la Seguridad Social que comprenderá la prestación de los servicios en la forma que determine la Ley.

La Seguridad Social podrá ser prestada por entidades públicas o privadas, de conformidad con la ley. No se podrán destinar ni utilizar los recursos de las instituciones de la Seguridad Social para fines diferentes a ella.

La ley definirá los medios para que los recursos destinados a pensiones mantengan su poder adquisitivo constante.

\section{Acto legislativo 01 de 2005}

Inciso adicionado por el artículo 1 del Acto Legislativo 1 de 2005. El nuevo texto es el siguiente:

El Estado garantizará los derechos, la sostenibilidad financiera del Sistema Pensional, respetará los derechos adquiridos con arreglo a la ley y asumirá el pago de la deuda pensional que de acuerdo con la ley esté a su cargo. Las leyes en materia pensional que se expidan con posterioridad a la entrada en vigencia de este acto legislativo, deberán asegurar la sostenibilidad financiera de lo establecido en ellas.

Inciso adicionado por el artículo 1 del Acto Legislativo 1 de 2005. El nuevo texto es el siguiente:

Sin perjuicio de los descuentos, deducciones y embargos a pensiones ordenados de acuerdo con la ley, por ningún motivo podrá dejarse de pagar, congelarse o reducirse el valor de la mesada de las pensiones reconocidas conforme a derecho.

Inciso adicionado por el artículo 1del Acto Legislativo 1 de 2005. El nuevo texto es el siguiente:

Para adquirir el derecho a la pensión será necesario cumplir con la edad, el tiempo de servicio, las semanas de cotización o el capital necesario, así como las demás condiciones que señala la ley, sin perjuicio de lo dispuesto para las pensiones de invalidez y sobrevivencia. Los requisitos y beneficios para adquirir el derecho a una pensión de invalidez o de sobrevivencia serán los establecidos por las leyes del Sistema General de Pensiones.

Inciso adicionado por el artículo 1 del Acto Legislativo 1 de 2005. El nuevo texto es el siguiente:
En materia pensional se respetarán todos los derechos adquiridos.

Inciso adicionado por el artículo 1 del Acto Legislativo 1 de 2005. El nuevo texto es el siguiente:

Los requisitos y beneficios pensiónales para todas las personas, incluidos los de pensión de vejez por actividades de alto riesgo, serán los establecidos en las leyes del Sistema General de Pensiones. No podrá dictarse disposición o invocarse acuerdo alguno para apartarse de lo allí establecido.

Inciso adicionado por el artículo 1 del Acto Legislativo 1 de 2005. El nuevo texto es el siguiente:

Para la liquidación de las pensiones sólo se tendrán en cuenta los factores sobre los cuales cada persona hubiere efectuado las cotizaciones. Ninguna pensión podrá ser inferior al salario mínimo legal mensual vigente. Sin embargo, la ley podrá determinar los casos en que se puedan conceder beneficios económicos periódicos inferiores al salario mínimo, a personas de escasos recursos que no cumplan con las condiciones requeridas para tener derecho a una pensión.

Inciso adicionado por el artículo 1 del Acto Legislativo 1 de 2005. El nuevo texto es el siguiente:

A partir de la vigencia del presente Acto Legislativo, no habrá regímenes especiales ni exceptuados, sin perjuicio del aplicable a la fuerza pública, al Presidente de la República y a lo establecido en los parágrafos del presente artículo.

Inciso adicionado por el artículo 1 del Acto Legislativo 1 de 2005. El nuevo texto es el siguiente:

Las personas cuyo derecho a la pensión se cause a partir de la vigencia del presente Acto Legislativo no podrán recibir más de trece (13) mesadas pensiónales al año. Se entiende que la pensión se causa cuando se cumplen todos los requisitos para acceder a ella, aún cuando no se hubiese efectuado el reconocimiento.

Inciso adicionado por el artículo $\underline{1}$ del Acto Legislativo 1 de 2005. El nuevo texto es el siguiente:

La ley establecerá un procedimiento breve para la revisión de las pensiones reconocidas con abuso del derecho o sin el cumplimiento de los requisitos establecidos en la ley o en las convenciones y laudos arbitrales válidamente celebrados. 
Parágrafo 1o. Parágrafo adicionado por el artículo 1 del Acto Legislativo 1 de 2005. El nuevo texto es el siguiente: A partir del 31 de julio de 2010, no podrán causarse pensiones superiores a veinticinco (25) salarios mínimos legales mensuales vigentes, con cargo a recursos de naturaleza pública.

Parágrafo 2o. Parágrafo adicionado por el artículo 1 del Acto Legislativo 1 de 2005. El nuevo texto es el siguiente: A partir de la vigencia del presente Acto Legislativo no podrán establecerse en pactos, convenciones colectivas de trabajo, laudos o acto jurídico alguno, condiciones pensiónales diferentes a las establecidas en las leyes del Sistema General de Pensiones.

Parágrafo Transitorio 3o. Parágrafo adicionado por el artículo 1 del Acto Legislativo 1 de 2005. El nuevo texto es el siguiente:

Las reglas de carácter pensional que rigen a la fecha de vigencia de este Acto Legislativo contenidas en pactos, convenciones colectivas de trabajo, laudos o acuerdos válidamente celebrados, se mantendrán por el término inicialmente estipulado. En los pactos, convenciones o laudos que se suscriban entre la vigencia de este Acto Legislativo y el 31 de julio de 2010, no podrán estipularse condiciones pensiónales más favorables que las que se encuentren actualmente vigentes. En todo caso perderán vigencia el 31 de julio de 2010.

Parágrafo Transitorio 4o. Parágrafo adicionado por el artículo 1 del Acto Legislativo 1 de 2005.

El nuevo texto es el siguiente: El régimen de transición establecido en la Ley 100 de 1993 y demás normas que desarrollen dicho régimen, no podrá extenderse más allá del 31 de julio de 2010; excepto para los trabajadores que estando en dicho régimen, además, tengan cotizadas al menos 750 semanas o su equivalente en tiempo de servicios a la entrada en vigencia del presente Acto Legislativo, a los cuales se les mantendrá dicho régimen hasta el año 2014. Los requisitos y beneficios pensiónales para las personas cobijadas por este régimen serán los exigidos por el artículo $\underline{36}$ de la Ley 100 de 1993 y demás normas que desarrollen dicho régimen.

Parágrafo Transitorio 5o. Parágrafo adicionado por el artículo 1 del Acto Legislativo 1 de 2005. El nuevo texto es el siguiente:

De conformidad con lo dispuesto por el artículo 140 de la Ley 100 de 1993 y el Decreto 2090 de 2003, a partir de la entrada en vigencia de este último de- creto, a los miembros del cuerpo de custodia y vigilancia Penitenciaria y Carcelaria Nacional se les aplicará el régimen de alto riesgo contemplado en el mismo. A quienes ingresaron con anterioridad a dicha fecha se aplicará el régimen hasta ese entonces vigente para dichas personas por razón de los riesgos de su labor, este es el dispuesto para el efecto por la Ley 32 de 1986, para lo cual deben haberse cubierto las cotizaciones correspondientes.

Parágrafo Transitorio 6o. Parágrafo adicionado por el artículo 1 del Acto Legislativo 1 de 2005. El nuevo texto es el siguiente:

Se exceptúan de lo establecido por el inciso 8o. del presente artículo, aquellas personas que perciban una pensión igual o inferior a tres (3) salarios mínimos legales mensuales vigentes, si la misma se causa antes del 31 de julio de 2011, quienes recibirán catorce (14) mesadas pensiónales al año.

Articulo 44. Constitución Nacional: Son derechos fundamentales de los niños: la vida, la integridad física, la salud y la seguridad social, la alimentación equilibrada, su nombre y nacionalidad, tener una familia y no ser separados de ella, el cuidado y amor, la educación y la cultura, la recreación y la libre expresión de su opinión. Serán protegidos contra toda forma de abandono, violencia física o moral, secuestro, venta, abuso sexual, explotación laboral o económica y trabajos riesgosos. Gozarán también de los demás derechos consagrados en la Constitución, en las leyes y en los tratados internacionales ratificados por Colombia.

La familia, la sociedad y el Estado tienen la obligación de asistir y proteger al niño para garantizar su desarrollo armónico e integral y el ejercicio pleno de sus derechos. Cualquier persona puede exigir de la autoridad competente su cumplimiento y la sanción de los infractores.

Los derechos de los niños prevalecen sobre los derechos de los demás.

Articulo 46. Constitución Nacional: El Estado, la sociedad y la familia concurrirán para la protección y la asistencia de las personas de la tercera edad y promoverán su integración a la vida activa y comunitaria.

El Estado les garantizará los servicios de la seguridad social integral y el subsidio alimentario en caso de indigencia. 
Articulo 47. Constitución Nacional: El Estado adelantará una política de previsión, rehabilitación e integración social para los disminuidos físicos, sensoriales y psíquicos, a quienes se prestará la atención especializada que requieran

Articulo 49. Constitución Nacional: La atención de la salud y el saneamiento ambiental son servicios públicos a cargo del Estado. Se garantiza a todas las personas el acceso a los servicios de promoción, protección y recuperación de la salud.

Corresponde al Estado organizar, dirigir y reglamentar la prestación de servicios de salud a los habitantes y de saneamiento ambiental conforme a los principios de eficiencia, universalidad y solidaridad. También, establecer las políticas para la prestación de servicios de salud por entidades privadas, y ejercer su vigilancia y control. Así mismo, establecer las competencias de la Nación, las entidades territoriales y los particulares y determinar los aportes a su cargo en los términos y condiciones señalados en la ley.

Los servicios de salud se organizarán en forma descentralizada, por niveles de atención y con participación de la comunidad.

La ley señalará los términos en los cuales la atención básica para todos los habitantes será gratuita y obligatoria.

Toda persona tiene el deber de procurar el cuidado integral de su salud y de su comunidad.

El porte y el consumo de sustancias estupefacientes o sicotrópicas está prohibido, salvo prescripción médica. Con fines preventivos y rehabilitadores la ley establecerá medidas y tratamientos administrativos de orden pedagógico, profiláctico o terapéutico para las personas que consuman dichas sustancias. El sometimiento a esas medidas y tratamientos requiere el consentimiento informado del adicto.

Así mismo el Estado dedicará especial atención al enfermo dependiente o adicto y a su familia para fortalecerla en valores y principios que contribuyan a prevenir comportamientos que afecten el cuidado integral de la salud de las personas y, por consiguiente, de la comunidad, y desarrollará en forma permanente campañas de prevención contra el consumo de drogas o sustancias estupefacientes y en favor de la recuperación de los adictos.
Articulo 50. Constitución Nacional: Todo niño menor de un año que no esté cubierto por algún tipo de protección o de seguridad social, tendrá derecho a recibir atención gratuita en todas las instituciones de salud que reciban aportes del Estado. La ley reglamentará la materia.

Por último en lo que respecta a los artículos 356 y 357 de la Constitución Nacional se puede decir que estos hacen referencia al sistema general de participaciones de los departamentos, distritos y municipios, y se señala como van a ser distribuidos los recursos del sistema de seguridad social, en donde prevalecen debe los servicios de salud, educación y cobertura del sistema

Ahora bien frente a si la seguridad social es un derecho fundamental o no se debe decir que ha habido diferentes criterios sobre este punto, y aun no se ha logrado unificar dichos criterios por parte de la jurisprudencia y la doctrina, sin embargo podemos decir que los derechos fundamentales se encuentran consagrados de manera taxativa en nuestra carta magna, además de esto los derechos que conforman la seguridad social, en muchas ocasiones requieren de una especial e inmediata protección que de no ser así se estaría atentando contra derechos fundamentales, como sería el caso del derecho a la Salud o el tan protegido derecho a la vida.

Sin embargo hay que resaltar que no todos los derechos que están inmersos en la seguridad social se puede considerar que tiene el carácter de fundamentales, por lo cual es necesario hacer un estudio de cada caso en particular.

Lo que si se podría afirmar es que la seguridad social se considerara un derecho fundamental específicamente cuando se vean afectados los derechos de los niños y de la personas de la tercera edad que se encuentren en un estado de desprotección, también adquiere el carácter de fundamental a la luz del art 48 de la Constitucion Nacional cuando señala: La Seguridad Social es un servicio público de carácter obligatorio que se prestará bajo la dirección, coordinación y control del Estado, en sujeción a los principios de eficiencia, universalidad y solidaridad, en los términos que establezca la Ley.

Se garantiza a todos los habitantes el derecho irrenunciable a la Seguridad Social., en los demás casos siempre habrá de hacerse un estudio de conexidad en el cual se pueda comportar que un determinado derecho respecto de otro derecho se reviste con el carácter de fundamental.

\section{Antecedentes históricos de las pensiones en Colombia}

Es preciso remontarse a la época de la independencia en donde se reconoció por primera vez al libertador Simón 
Bolívar pensión como reconocimiento a su labor en la lucha por la causa independentista, esta pensión se financio con recursos del erario público.

Colombia tomó como modelo una institución de origen español denominada Montepío militar la cual estaba conformada por los militares españoles y cuyo objetivo era ayudar a quienes se encontraban librando alguna batalla, así mismo a las viudas y huérfanos de los militares que habían perdido la vida en alguna batalla de la época.

Colombia tomó como modelo esta institución para la previsión y cubrimiento de algunos riesgos, la cual tuvo como fin primordial proporcionar ayudas económicas a las viudas y familiares de los héroes que habían perdido la vida en alguna batalla de la época de la independencia, para lo cual se conformo un fondo el cual tuvo como fuente de financiamiento dineros que se descontaban a los sueldos y pensiones a los generales y oficiales del ejército y de la marina.

\section{Constitución Política colombiana de 1886}

En el artículo 62 de la constitución de 1886 se consagro que:

La ley determinará los casos particulares de incompatibilidad de funciones; los de responsabilidad de los funcionarios y modo de hacerla efectiva; las calidades y antecedentes necesarios para el desempeño de ciertos empleos, en los casos no previstos por la Constitución; las condiciones de ascenso y de jubilación; y la serie o clase de servicios civiles o militares que dan derecho a pensión del Tesoro público.

\section{Ley 50 de 1886}

Estableció reglas generales acerca de la concesión de pensiones y jubilaciones y estableció tres artículos relevantes en materia pensional.

Artículo 5o. Toda pensión del Tesoro nacional es por su naturaleza la recompensa de grandes o largos servicios hechos a la Patria, según la condición social del pensionado, sea por este mismo, sea por su padre, abuelo, hijo o esposo, si en el segundo caso la invalidez o pobreza del peticionario proviene de tales servicios. En consecuencia, las pensiones, así civiles, como militares, tienen el carácter de exclusivamente personales, y en ningún caso serán hereditarias, en todo ni en parte, a beneficio de ningún copartícipe en ellas o de ningún pariente de los pensionados. Cuando fallezca algún pensionado, su pensión quedará cancelada, caducando en cuanto a él, en la parte respectiva, la ley que la haya concedido o aumentado.

Artículo 11. Los empleados civiles que hayan desempeñado destinos o empleos de manejo, judiciales o políticos por vente años por lo menos, con inteligencia y pureza, que comprueben con documentos auténticos sus servicios y que no han sufrido alcance ni remoción por mal manejo, incuria u omisión, tienen derecho a pensión de jubilación, siempre que comprueben en los términos prescritos por esta ley, justa opción a recompensa, en estos casos: 1o. Haberse inutilizado en el servicio y no tener medios de procurarse la subsistencia, o bien ser mayor de sesenta años; 20 . No haber sido rebelde ni sindicado de tal contra el Gobierno bajo cuyo servicio se ha hallado; 3o. No haber sido acusado ni tildado de prevaricador".

Artículo 18. Son pensiones remuneratorias:

1o. Las concedidas a los militares de la Independencia por servicios prestados a aquella causa desde 1810 a 1826 inclusive, y en la Marina de Guerra hasta 1827 ;

2o. Las concedidas a título de jubilación o retiro, en premio de servicios clasificados en ley preexistente, siempre que en su cuantía y términos la concesión se haya ceñido a la promesa legal.

Las pensiones remuneratorias de que trata este artículo no podrán disminuirse en tiempo; y serán pagadas mensualmente en moneda legal."

\section{Ley 39 de 1903}

Se refiere a la pensión para los maestros, profesores e inspectores de instrucción pública.

\section{Ley 29 de 1905}

Estableció un régimen pensional para los magistrados de la corte suprema de justicia mayores a 60 años, quienes se jubilarían con la mitad del sueldo del cargo en el que se hubieran desempeñado.

\section{Ley 29 de 1912}

Estableció las pensiones para las viudas de los ciudadanos que hayan desempeñado la presidencia de la repúbli$\mathrm{ca}$, y en su defecto las hijas solteras.

\section{Ley 57 de 1915}

Implementó el término accidente de trabajo en nuestra legislación.

\section{Ley 37 de 1921}

Instauró el seguro de vida colectivo para las empresas que tuvieran el carácter de permanente. 


\section{Ley 40 de 1922}

Pensiones a favor de aquellos militares, médicos y empleados que hubieran sido contagiados con lepra en los lazaretos.

\section{Ley 86 de 1923}

Los empleados públicos de orden nacional, que hayan contraído una enfermedad adquirida durante la prestación del servicio o posterior a este, y que lo límite para realizarlo tendrá derecho a la mitad del sueldo devengado por el termino de 6 meses.

\section{Ley 37 de 1925}

Creó el fondo de la caja de sueldos de retiro de las fuerzas militares.

\section{Ley 15 de 1925}

Consagró los primeros aspectos en materia de salud ocupacional y la garantía de atención en salud pública a los sectores más desfavorecidos.

\section{Ley 116 de 1926}

Establecieron los requisitos para la pensión de jubilación los maestros.

\section{Ley 102 de 1927}

Derecho a la pensión de las viudas de los magistrados de la corte suprema de justicia y los tribunales superiores de distrito judicial, que hubieren servido por más de 20 años a la Rama judicial.

\section{Ley 114 de 1934}

Estableció los requisitos para la pensión de los maestros.

\section{Ley 10 de 1934}

Implementó el auxilio de cesantía para los empleados particulares.

\section{Decreto 2350 de 1944:}

Dispuso en su artículo 8 lo siguiente: mientras se organiza el seguro social obligatorio, corresponderán también al patrono además de las que les impongan las leyes especiales o convenciones de trabajo las siguientes indemnizaciones o prestaciones para con sus trabajadores, ya sean empleados $\mathrm{u}$ obreros. Se fijaron indemnizaciones por accidentes de trabajo, se definió lo que es accidente de trabajo, se establecieron lo que son las enfermedades profesionales, también se creó el auxilio por enfermedad no profesional.

\section{Ley 6ta de 1945}

Organizó de mejor forma todo el sistema prestacional existente, obligo a los patronos a pagar indemnizaciones por accidentes de trabajo, con esta ley se ordeno la creación del Instituto de Colombiano de los Seguros Sociales.
Estableció la pensión de jubilación para quienes cumplieren 50 años de edad y 20 años de servicio continuo o discontinuo, por ultimo estableció el monto de la pensión sería equivalente a las $2 / 3$ partes del promedio del salario devengando en el último año de servicio.

\section{Decreto ley 1600 de 1945}

Creó la caja de previsión social para cubrir todo lo concerniente a riesgos de los servidores públicos.

\section{Ley 90 de 1946}

Su más importante aporte fue que creó el Instituto de Colombiano de los Seguros Sociales, además de esto consagro que todas las empresas de carácter particular debían afiliar a sus trabajadores para que así se diera el cubrimiento y subrogación de los riesgos derivados de la invalidez, vejez y la muerte. Un aspecto importante a destacar es que en el país el cubrimiento de los riesgos no se dio en forma inmediata pues estos solo entraron en vigencia a partir del año 1967 a través del decreto 3041 de 1966, sin embargo en la Costa atlántica su cubrimiento se dio en el año 1968 (Muñoz Osorio, 2012). Ahora bien por medio de los decretos 2663 y 3743 de 1950 equivalentes al artículo 260 del código sustantivo del trabajo se estableció la pensión mínima de jubilación, la cual tenía como requisitos, que el trabajador que prestare sus servicios a una misma empresa cuyo capital fuere de $\$ 800.000$. O superior, que tuviera 55 años si era hombre y 50 años si era mujer, después de 20 años de servicio continuo o discontinuo, anteriores o posteriores a la vigencia de dicho código adquirían el derecho a una pensión mensual vitalicia de jubilación o de vejez equivalente al 75\% del promedio de los salarios devengados en el último año de servicio.

Otro punto que es pertinente resaltar es lo concerniente a que al momento de emitirse la constituyente 1991, el cubrimiento pensional para los servidores públicos del orden nacional, departamental y municipal estaba regido por múltiples cajas y fondos de previsión para ser más precisos 1004 cajas eran las que se encargaban de manejar el cubrimiento pensional en el campo del estado. Esta situación sumada a que transcurrieron más de 20 años para que se expidiera el primer reglamento general de seguros social obligatorio, ocasiono caos en materia de las normas pensiónales dado que expidieron muchas leyes sobre pensiones (Rodríguez Meza 2012).

Ley 4ta de 1966, realizo una reforma a la ley 6ta de 1945 y estableció que el monto de la pensión sería equivalente al $75 \%$ del promedio del último año de servicio.

Decreto 3135 de 1968 y su reglamentario 1849 de 1969: reorganizan el sistema prestacional general de los servidores del estado de carácter nacional. 
Decreto ley 3135 de 1985 hizo diferencia en las edades de pensión de jubilación de los servidores públicos 55 años para los hombres, 50 años para las mujeres.

Ley 33 de 1985, con esta ley se hace una nueva reforma a las edades de pensión de los servidores públicos, puesto que unifica la edad para ambos sexos y la deja en 55 años.

Acuerdo 049 de 1990, su mayor aporte fue que realizó modificaciones a los requisitos para acceder a la pensión de vejez puesto que los hombres debían contar con 60 años de edad y las mujeres con 55 años, además se exigía que tuvieran 500 semanas cotizadas que se contaban dentro de los últimos 20 años de servicio (Muñoz Osorio, 2012).

\section{Ley 100 de 1993}

Se encargó de Organizar el sistema integral de seguridad social con el objeto de garantizar los derechos irrenunciables de las personas, teniendo en cuenta que siendo Colombia un estado social de derecho prima la dignidad humana y por ende el estado Colombiano debe garantizar la protección de los habitantes del territorio nacional, mediante el cubrimiento de todas las contingencias que se puedan presentar.

Según esta ley el sistema está conformado de la siguiente manera artículo 8 de la ley 100 de 1993:

Artículo 8o. Conformación del sistema de seguridad social integral. El Sistema de Seguridad Social Integral es el conjunto armónico de entidades públicas y privadas, normas y procedimientos y está conformado por los regímenes generales establecidos para pensiones, salud, riesgos profesionales y los servicios sociales complementarios que se definen en la presente ley".

\section{Las leyes 797 y 860 de 2003}

Reformaron algunas disposiciones del sistema general de pensiones contemplados en la Ley 100 y adoptaron disposiciones sobre los regímenes especiales y exceptuados.

\section{Obligatoriedad de afiliación al sistema pensional colombiano}

Para empezar a hablar de obligatoriedad de la afiliación, se debe definir el concepto de afiliación que consiste, en el conjunto de derechos y obligaciones que hay entre la administradora y el afiliado, frente al sistema de seguridad social. La naturaleza de la afiliación podríamos decir que es un vínculo de carácter contractual, que no está al arbitrio del querer de las partes, dado que la afiliación está consagrada en nuestra ley.
Ahora bien en el sistema pensional colombiano cuenta con dos clases de afiliados, unos que son de carácter obligatorio y unos de carácter voluntario.

Obligatorios se encuentran consagrados en la ley 100 art 15, modificado por la ley 797 articulo 3 y estos son:

- Todas aquellas personas vinculadas mediante contrato de trabajo o como servidores públicos, es decir todas aquellas personas que se encuentran en una subordinación o dependencia con un patrono que puede ser de carácter público o privado.

- Antes de la ley 797 de 2003 los empleados de Ecopetrol hacían parte de un régimen exceptuado, al entrar en vigencia esta ley los servidores públicos que ingresen a Ecopetrol son afiliados obligatorios.

- Decreto 692 de 1994 art.9 son también afiliados obligatorios al sistema, los servidores públicos de la rama ejecutiva del orden nacional, departamental, municipal o distrital, al igual que sus entidades descentralizadas.

- Decreto 691 de 1994 art. 1 servidores públicos del congreso, rama judicial, ministerio público, fiscalía, organización electoral y contraloría.

- Personas que presten directamente servicios al estado o a las entidades o empresas del sector privado, bajo la modalidad de contratos de prestación de servicios o cualquier otra modalidad. Con la entrada en vigencia de la ley 797 de 2033 se dispuso que los contratistas de entidades públicas y privadas son afiliados obligatorios al sistema. Pese a esto hay que aclarar que continua vigente el artículo 282 de la ley de 1993 que consagra que cuando el contratistas tenga un contrato igual o inferior a tres meses, este no se encuentra obligado a demostrar afiliación al sistema.

- Son de igual manera afiliados obligatorios al sistema los trabajadores independientes.

- Por último son afiliados obligatorios al sistema todas aquellas personas que por sus condiciones económicas son sujetos para ser beneficiarios de subsidios a través del fondo de solidaridad pensional.

Afiliados voluntarios al sistema pensional:

- Residentes en el país y colombianos en el exterior que no tenga la calidad de afiliados obligatorios.

- Extranjeros que en virtud de un contrato de trabajo permanezcan en el país y no estén cubiertos por algún régimen de origen o cualquier otro.

\section{Las reformas al sistema pensional colombiano (después de ley 100/93)}

Mediante la ley 100 de 1993, se pretendió organizar el sistema de seguridad social con el único fin de amparar 
los derechos y cobertura al sistema de todos los habitantes del territorio nacional, esta reforma se dio mediante el gobierno de Cesar Gaviria, posterior a este gobierno durante el mandato de Ernesto Samper Pizano se implementaron políticas tendientes a la organización y ajustes del nuevo sistema, sin que se produjeran muchos avances en materia de esta ley. Para el año de 1998 cuando el presidente Andrés Pastrana evaluó que avances había tenido la ley, el resultado que arrojo esta evaluación fue que no se había avanzado en materia de cobertura, había un déficit fiscal grande, y además existía mucha inequidad, con lo que se llegó a pensar que se necesitaría nuevos reajustes normativos.

\section{Ley 797 de 2003}

Con la implementación de esta nueva ley en el sistema pensional colombiano se busco introducir al sistema algunos aspectos fundamentales que fueron:

1. Fortalecimiento en las cotizaciones: Se dispuso en ambos regímenes pensiónales aumentos en las cotizaciones en forma porcentual a partir de 2004.

2. Introdujo recorte de beneficios en el régimen de prima media, se aumento el tiempo mínimo de cotización para obtener la pensión, se disminuyo la cuantía de la pensión, al señalarse una formula decreciente que dispones un monto entre el 65 y el $55 \%$ del ingreso base, se establecieron múltiples exigencias adicionales para el reconocimiento de la pensión de invalidez y de sobrevivientes.

3. Esta ley abordo al tema de los subsidios en el sistema pensional, es sabido que en un primer momento los sistemas de pensiones son en un principio exclusivamente contributivos, pero además de esto existe una marcada tendencia a que estos sistemas contribuyan a la erradicación de la pobreza extrema, con la ley 797 se fortaleció el Fondo de Solidaridad Pensional, el cual cuenta con una subcuenta para subsidios pensiónales de subsistencia para los ancianos en situación de indigencia, con fuentes especificas de financiamiento a través de cotizaciones adicionales de los afiliados de mayor ingreso.

\section{Ley 860 de 2003}

Con esta ley el gobierno nacional modifico el régimen de transición que se encontraba consagrado en la ley 100 de 1993, la modificación se dio en los requisitos de la edad, tiempo y monto de pensión del régimen anterior se conservaba hasta el mes de diciembre de 2007; y a partir de 2008 se solo se respetaría la edad del régimen anterior y las demás condiciones serian las de la ley 100 con las modificaciones de la ley 797. Sin embargo la reforma a la transición introducida en esta ley fue declara inexequible por la corte Constitucional en sentencia C-754 de
2004, teniendo como fundamento que existían vicios de procedimientos en el trámite de la ley, además de esto se encargo de precisar acerca de los conceptos de derechos adquiridos y simples expectativas, estas últimas pueden denominarse expectativa legitima o derecho a un régimen que no pueden modificarse una vez establecidas.

La honorable corte en esta sentencia se encarga de explicar que una cosa es el derecho a pensionarse que se adquiere una vez se cumple con los requisitos edad y semanas cotizadas y otra muy distinta es el derecho a permanecer en un determinado régimen con el cual se protege a las personas que sin haber alcanzado el beneficio están próximas a adquirirlo.

\section{Acto legislativo 01 de 2005}

Otra figura que hizo modificaciones a la ley 100 de 1993 fue el acto legislativo 01 de 2005, el cual realizo modificaciones en lo concerniente al régimen de transición ya que dicho régimen no podría extenderse más allá del 31 de julio de 2010, excepto para los trabajadores que estando en dicho régimen además tengan cotizadas 750 semanas o su equivalente en tiempo de servicios a la entrada en vigencia del acto legislativo a los cuales se les mantendrá dicho régimen hasta el año 2014. Los requisitos y beneficios pensionales para las personas cobijadas por este régimen, serán los exigidos por el artículo 36 de la ley 100 y demás normas que se desarrollen en dicho régimen.

\section{La jurisprudencia constitucional garantiza la protección a la seguridad social}

Es necesario hacer mención de la jurisprudencia constitucional ya que esta alta corte ha hecho interpretaciones constitucionales pronunciándose al respecto y propendiendo por la salvaguarda de la seguridad social de las personas que llegan a una edad en donde las fuerzas físicas han declinado e impidiéndose de esta forma que puedan seguir con las actividades laborales que hasta ese momento venían desarrollando.

En el sistema general de pensiones se han aplicando principios tales como el de universalidad, solidaridad, equidad que son principios propios del sistema de seguridad social así mismo se ha hecho aplicación de principios consagrados en la carta magna de 1991 tales como el principio de igualdad art 13 , debido proceso art 29 , irrenunciabilidad de beneficios mínimo art 48,53, mínimo vital art 53 , entre otros.

Con base en lo anterior se le da una visión diferente a los problemas de los pensionados colombianos, la jurisprudencia nacional hoy día se ha multiplicado y es por ello que existen numerosas sentencias que brindan protección a este grupo de la población que se encuentra en un es- 
tado de vulnerabilidad, al haberse disminuido su capacidad laboral y con ello su generación de ingreso que le permita un mínimo vital para su sustento y en algunos eventos este ingreso no solo es para cubrir las necesidades básicas primarias de esa persona que a lo largo de su vida laboral hizo los aportes al sistema sino que este ingreso cubre también las necesidades de su núcleo familiar, es así como el artículo 48 de la constitución nacional que fue adicionado por el acto legislativo de 2005, respecto al sistema pensional consagra:

“El Estado garantizará los derechos, la sostenibilidad financiera del Sistema Pensional, respetará los derechos adquiridos con arreglo a la ley y asumirá el pago de la deuda pensional que de acuerdo con la ley esté a su cargo. Las leyes en materia pensional que se expidan con posterioridad a la entrada en vigencia de este acto legislativo, deberán asegurar la sostenibilidad financiera de lo establecido en ellas".

"Sin perjuicio de los descuentos, deducciones y embargos a pensiones ordenados de acuerdo con la ley, por ningún motivo podrá dejarse de pagar, congelarse o reducirse el valor de la mesada de las pensiones reconocidas conforme a derecho".

"Para adquirir el derecho a la pensión será necesario cumplir con la edad, el tiempo de servicio, las semanas de cotización o el capital necesario, así como las demás condiciones que señala la ley, sin perjuicio de lo dispuesto para las pensiones de invalidez y sobrevivencia. Los requisitos y beneficios para adquirir el derecho a una pensión de invalidez o de sobrevivencia serán los establecidos por las leyes del Sistema General de Pensiones".

"En materia pensional se respetarán todos los derechos adquiridos".

“Los requisitos y beneficios pensiónales para todas las personas, incluidos los de pensión de vejez por actividades de alto riesgo, serán los establecidos en las leyes del Sistema General de Pensiones. No podrá dictarse disposición o invocarse acuerdo alguno para apartarse de lo allí establecido".

“Para la liquidación de las pensiones sólo se tendrán en cuenta los factores sobre los cuales cada persona hubiere efectuado las cotizaciones. Ninguna pensión podrá ser inferior al salario mínimo legal mensual vigente. Sin embargo, la ley podrá determinar los casos en que se puedan conceder beneficios económicos periódicos inferiores al salario mínimo, a personas de escasos recursos que no cumplan con las condiciones requeridas para tener derecho a una pensión".
"A partir de la vigencia del presente Acto Legislativo, no habrá regímenes especiales ni exceptuados, sin perjuicio del aplicable a la fuerza pública, al Presidente de la República y a lo establecido en los parágrafos del presente artículo".

"Las personas cuyo derecho a la pensión se cause a partir de la vigencia del presente Acto Legislativo no podrán recibir más de trece (13) mesadas pensiónales al año. Se entiende que la pensión se causa cuando se cumplen todos los requisitos para acceder a ella, aún cuando no se hubiese efectuado el reconocimiento".

"La ley establecerá un procedimiento breve para la revisión de las pensiones reconocidas con abuso del derecho o sin el cumplimiento de los requisitos establecidos en la ley o en las convenciones y laudos arbitrales válidamente celebrados".

“Parágrafo $\mathbf{1}^{\circ}$. A partir del 31 de julio de 2010, no podrán causarse pensiones superiores a veinticinco (25) salarios mínimos legales mensuales vigentes, con cargo a recursos de naturaleza pública".

"Parágrafo $2^{\circ}$. A partir de la vigencia del presente Acto Legislativo no podrán establecerse en pactos, convenciones colectivas de trabajo, laudos o acto jurídico alguno, condiciones pensiónales diferentes a las establecidas en las leyes del Sistema General de Pensiones".

“Parágrafo transitorio $\mathbf{1}^{\mathrm{o}}$. El régimen pensional de los docentes nacionales, nacionalizados y territoriales, vinculados al servicio público educativo oficial es el establecido para el Magisterio en las disposiciones legales vigentes con anterioridad a la entrada en vigencia de la Ley 812 de 2003, y lo preceptuado en el artículo 81 de esta. Los docentes que se hayan vinculado o se vinculen a partir de la vigencia de la citada ley, tendrán los derechos de prima media establecidos en las leyes del Sistema General de Pensiones, en los términos del artículo 81 de la Ley 812 de 2003".

"Parágrafo transitorio $2^{\circ}$. Sin perjuicio de los derechos adquiridos, el régimen aplicable a los miembros de la Fuerza Pública y al Presidente de la República, y lo establecido en los parágrafos del presente artículo, la vigencia de los regímenes pensionales especiales, los exceptuados, así como cualquier otro distinto al establecido de manera permanente en las leyes del Sistema General de Pensiones expirará el 31 de julio del año 2010".

“Parágrafo transitorio $3^{\circ}$. Las reglas de carácter pensional que rigen a la fecha de vigencia de este Acto Legislativo contenidas en pactos, convenciones colectivas de trabajo, laudos o acuerdos válidamente celebrados, se 
mantendrán por el término inicialmente estipulado. En los pactos, convenciones o laudos que se suscriban entre la vigencia de este Acto Legislativo y el 31 de julio de 2010, no podrán estipularse condiciones pensiónales más favorables que las que se encuentren actualmente vigentes. En todo caso perderán vigencia el 31 de julio de 2010".

"Parágrafo transitorio $4^{\circ}$. El régimen de transición establecido en la Ley 100 de 1993 y demás normas que desarrollen dicho régimen, no podrá extenderse más allá del 31 de julio de 2010; excepto para los trabajadores que estando en dicho régimen, además, tengan cotizadas al menos 750 semanas o su equivalente en tiempo de servicios a la entrada en vigencia del presente Acto Legislativo, a los cuales se les mantendrá dicho régimen hasta el año 2014".

"Los requisitos y beneficios pensiónales para las personas cobijadas por este régimen serán los exigidos por el artículo 36 de la Ley 100 de 1993 y demás normas que desarrollen dicho régimen".

"Parágrafo transitorio $5^{\circ}$. De conformidad con lo dispuesto por el artículo 140 de la Ley 100 de 1993 y el Decreto 2090 de 2003, a partir de la entrada en vigencia de este último decreto, a los miembros del cuerpo de custodia y vigilancia Penitenciaria y Carcelaria Nacional se les aplicará el régimen de alto riesgo contemplado en el mismo. A quienes ingresaron con anterioridad a dicha fecha se aplicará el régimen hasta ese entonces vigente para dichas personas por razón de los riesgos de su labor, este es el dispuesto para el efecto por la Ley 32 de 1986, para lo cual deben haberse cubierto las cotizaciones correspondientes".

"Parágrafo transitorio $6^{\circ}$. Se exceptúan de lo establecido por el inciso $8^{\circ}$ del presente artículo, aquellas personas que perciban una pensión igual o inferior a tres (3) salarios mínimos legales mensuales vigentes, si la misma se causa antes del 31 de julio de 2011, quienes recibirán catorce (14) mesadas pensiónales al año".

La corte suprema de justicia fue la primera institución que al momento de tener en sus manos el control constitucional la que le dio a la pensión el carácter de derecho adquirido y hablo del estatus del pensionado, sentando este alto tribunal el precedente con el fallo del 15 de marzo de 1968 cuando manifestó lo siguiente:

“Dondequiera que la ley ha consagrado la jubilación o la pensión en favor de los trabajadores o empleados que cumplan determinado tiempos de servicios, lleguen a cierta edad o reúnan especiales condiciones, se acepta unánimemente que al concurrir esos requisitos surge un derecho perfecto al beneficiario".
Después del fallo antes mencionado a fin de brindar protección al derecho a la seguridad en pensiones, la corte se ha pronunciado en reiteradas ocasiones mediante las sentencias que a continuación se señalan.

\section{Derecho subjetivo \\ Así se expresó en la sentencia T-1752/2000.}

Derecho adquirido. La sentencia C-027/95, Sentencia SU.430/98.

Derecho fundamental (jusfundamentalidad)

Sentencias: T-02/92, T-02/92, T-671/2000, C-177 de 1998, T-06/92, T111/94,

T-516/93， T-068/94，T-426/93，T-456/94， T-491/01, SU.1354/00

\section{Protección por conexidad}

Sentencia T-453/92.

Inmediatez a las peticiones del aspirante ha pensionado T-796/01，T-887/01，T-170 2000, T-491/01，T-671/00, $\mathrm{T}-1294$ de 2000 ,

T-684/01, T-1238/01, T-1187/01, T-900/2001, T-671/00, C-177, T-241, T-360, T-440, T-551 y T-549 de 1998, T-463/96, T-823/01T-1044/01, T-1187/01

\section{Régimen de transición}

Sentencia T-534/2001, T-235/02, T-098/2002, T-089/99, C-479/92, T-716/96,

C-1064/01, T-426 de 1992, T-1565/2000.

\section{Crisis del sistema pensional}

$\mathrm{Al}$ analizar la crisis en el sistema pensional en Colombia se debe tratar de ser lo más objetivo posible, ya que los medios de comunicación desde antes de la promulgación de la Ley 100, jugaron un papel preponderante en la estrategia encaminada a la privatización del sistema pensional en Colombia. Hoy día, estos medios, siguen al servicio del modelo neoliberal imperante en el país desde hace varios años, achacándole a los regímenes especiales (Congresistas, Magisterio, Fuerzas Militares, Ecopetrol) las causas de todos los males del sistema pensional colombiano. Lo anterior no es cierto, ya que ni el monto de las pensiones de los beneficiarios de los regímenes especiales es tan alto, ni el número de magistrados y congresistas pensionados pueden determinar el desequilibrio del sistema. Es algo común encontrar noticias en la prensa o en la radio y la televisión colombiana, en las que se proponen, como solución a la crisis de las pensiones en el país, el aumento de la edad de jubilación y del monto de las cotizaciones. Sin duda los problemas en la parte financiera inciden en 
una adecuada financiación de las pensiones, pero se debe tener presente que a esto se suman otros factores:

1. La maduración del sistema, es decir que muchas personas cotizantes activas pasan a pasivos y por ende a recibir su pensión, en nuestro país la maduración del sistema es a mediano plazo es decir el gobierno cada cierto tiempo aumenta la edad y el tiempo de semanas de cotización a fin de que el momento de maduración sea a más largo plazo. Los medios de comunicación cumplen su papel al sembrar, en la población, la idea de que con esa disminución de los beneficios se solucionan los problemas del sistema.

2. Globalización, cuando se pretenden ubicar las pensiones en el modelo neoliberal como elemento de contraste a la economía planificada, dentro del modelo neoliberal se da la llamada flexibilidad laboral y con ella se trasladan todos los problemas económicos del capitalista a los trabajadores.

3. Tendencias demográficas, es decir disminución de la tasa de natalidad, aumento de la vida probable, cambio de la estructura de la familia nuclear.

4. Desempleo, si muchas personas no cotizan se afecta financieramente el sistema.

5. La presencia de evasión en el sistema es decir no pago de las cotizaciones al sistema, y la elusión que es no pagar la debida cotización si no menos de lo que correspondería pagar.

6. Fallas en la gestión se propician deliberadamente para restarle legitimidad y credibilidad a un sistema en el que participa en forma activa el estado.

El maestro Rafael Rodríguez Meza, en su obra "Estudios Sobre Seguridad Social" hace un análisis exhaustivo acerca de la crisis del Sistema Pensional Colombiano desde sus inicios, es pertinente extraer algunos apartes importantes de dicha obra:

1. El Decreto 2350 de 1944 y la Ley 6 de de 1945 establecieron la subrogación bismarckiana del sistema de prestaciones sociales patronales al del seguro social obligatorio.

2. El Decreto 1600 de 1945 creó la Caja de Previsión Social, fundamentadas en este, surgieron cajas y fondos de previsión de orden nacional, departamental y municipal que trajeron una dispersión del sistema de tal magnitud que para el momento de la Asamblea Nacional Constituyente del 91 existían en el país 1004 cajas, fondos, y entidades que administraban pensiones en el sector estatal.

3. La Ley 90 de 1946 dio origen al ICSS. Sin embargo, desde su fundación, el instituto fue paquidérmico para aumentar la cobertura pensional, para llegar a las distintas regiones del país y para dar cumplimiento a lo establecido en la ley que lo creó: Transcurrieron más de 20 años para la expedición del primer Reglamento General del Seguro Social Obligatorio de IVM (Decreto 3041 de 1966). Es evidente el deterioro de las finanzas del sistema pensional del ISS por el incumplimiento sistemático del estado colombiano en el pago de los aportes que le correspondían (25\% de la cotización durante 5 años). Hasta el año 1973 la deuda acumulada alcanzaba los 9000 millones de pesos, que para el año 1993, año de expedición de la Ley 100, se podrían estimar en alrededor de 800.000 millones de pesos, esta deuda el estado decidió no cancelarla. Para el año 2010 los actuarios calculaban la deuda del estado con el seguro social en 2,2 billones de pesos, no se ha observado ni la voluntad política, ni se cuenta con los recursos para pagarla.

4. Solamente el $18.6 \%$ de los colombianos mayores de 65 años gozan de una pensión, uno de los niveles más bajos de protección pensional en Latinoamérica.

5. En el 2003, apenas el 46.1 de los asalariados aportaba a pensiones, proporción que se elevaba a $84.7 \%$ de los empleados del gobierno pero se reducía a 5.1 y $5.7 \%$ para los jornaleros y el servicio doméstico respectivamente.

6. Respecto a los trabajadores independientes, apenas el $7.9 \%$ está afiliado a pensiones, así: 10,5\% en las cabeceras municipales y el 1,9 en las zonas rurales.

7. La cobertura entre los grupos de menores ingresos se redujo entre 1992 y el 2000, solo aumentó para el 20\% de los asalariados de mayores ingresos. Mientras que en 1992 apenas el 7.1\% de los adultos mayores recibían una mesada pensional, en el 2000 la cifra cayó a $5.9 \%$. Durante ese mismo periodo, el $20 \%$ de los trabajadores de altos ingresos que percibían una pensión subió de 27.7 a $44.9 \%$, lo que indica inequidad en el sistema.

8. Cifras de 2008 del Departamento Nacional de Planeación (DNP) Indica que medida la informalidad laboral por los aportes a la seguridad social (pensiones, salud y riesgos profesionales), ésta supera fácilmente el $70 \%$.

Entre los problemas fundamentales contamos con que muchas personas desean la mercantilización de la seguridad social y para esto manipulan informes actuariales que tratan de trabajo informal, envejecimiento de la población, proceso de recaudación, fraude y desorganización, sumado a esto se encuentra el componente de la desigualdad en la repartición de la riquezas por que los ricos siempre son más ricos debido al sistema bajo el cual se rige el país que es el neoliberalismo y los pobres siempre son más pobres. 


\section{Conclusión}

Colombia es un Estado Social de Derecho, en donde la seguridad social se encuentra amparada por la Carta Magna en su artículo 48, adicionado por el acto legislativo 01 de 2005, dicho artículo tiene como uno de sus ejes fundamentales la protección y amparo de las personas de la tercera edad mediante la pensión de vejez.

Esta prestación económica es la que garantizará a las personas de la tercera edad los recursos mínimos para el cubrimiento de sus necesidades, tan es así que la Corte Constitucional Colombiana en varias jurisprudencias ha expresado que la pensión constituye un salario diferido del trabajador, fruto de su ahorro forzoso durante toda una vida de trabajo, es decir la pensión constituye el amparo de todas las contingencias que pueda sufrir una persona de la tercera edad, cuando las fuerzas laborales ya no son las mismas.

Acerca de si la pensión es un derecho fundamental o no, se puede resaltar que el Artículo 13 de la Constitución Política señala como una obligación a cargo del estado brindar una especial protección a aquellas personas que se encuentran en un estado de debilidad manifiesta y dentro de este grupo se encuentran las personas de la tercera edad. Las características de indefensión que acompañan a este grupo de personas permiten elevar a la categoría de fundamental el derecho a una pensión, por su conexidad, con derechos de rango superior como lo son: la vida, el mínimo vital, la dignidad humana, entre otros Díaz Sanabria (2012) contribuye a la aclaración del interrogante planteado: "Es así, entonces, que el derecho a la pensión adquiere la calidad de derecho fundamental en el entendido que con el no reconocimiento de esta, se estarían vulnerando derechos fundamentales de orden constitucional, y lo más importante, se estaría vulnerando el mínimo vital y móvil, que es el que le permite a las personas de la tercera edad suplir sus necesidades básicas". La jurisprudencia de la Corte Constitucional en las sentencias T-426 de 1993, T-516 de 1993, T-068 de 1994, y T-456 de 1994, expresa claramente que la seguridad social adquiere el carácter de fundamental, cuando las circunstancias del caso, su no reconocimiento, pongan en peligro otros derechos y principios fundamentales, como lo son: el derecho a la vida, a la dignidad humana, a la integridad física y moral, al libre desarrollo de la personalidad o los derechos de las personas de la tercera edad.

\section{Referencias}

Constitución Nacional de Colombia 1991.

Cartilla de Seguridad Social y Pensiones (2011). Bogotá- Colombia. Editorial Legis.

Díaz, Sanabria C. (2012). Estado y Derecho En Clave Constitucional, Editorial Universidad Pedagógica Tecnológica De Colombia. Tunja-Boyacá.

Defensoría del Pueblo. (2001). Estado Social y Democrático De Derecho y Derechos Humanos Bogotá Colombia.

Dueñas, Ruiz O, (2007) Las Pensiones, Teoría, Normas y Jurisprudencia en Colombia. Ediciones Librería del Profesional. Bogotá-Colombia

Monsalve, Arenas G (2011). El Derecho Colombiano De La Seguridad Social. Editorial Legis. Bogotá -Colombia.

Muñoz, Osorio A (2012) Revista Pensamiento Americano, Barranquill-. Editorial Corporación Universitaria Americana. Medellín-Colombia.

Quiroga, E. (2012). Estado y Derecho en Clave Constitucional, editorial, Universidad Pedagógica Tecnológica de Colombia, 2012.

Rodríguez, Mesa R (2010). Estudios Sobre Seguridad Social. Ediciones Uninorte. Barranquilla- Colombia.

\section{Legislación:}

República de Colombia. Acto Legislativo 01 de 2005. 
República de Colombia. Ley 100 de 1993.

República de Colombia. Ley 797 de 1993.

República de Colombia. Ley 50 de 1886.

República de Colombia. Ley 39 de 1903.

República de Colombia. Ley 29 de 1905.

República de Colombia. Ley 29 de 1912.

República de Colombia. Ley 57 de 1915.

República de Colombia. Ley 37 de 1921.

República de Colombia. Ley 40 de 1922.

República de Colombia. Ley 86 de 1923.

República de Colombia. Ley 37 de 1925.

República de Colombia. Ley 15 de 1925.

República de Colombia. Ley 116 de 1926.

República de Colombia. Ley 102 de 1927.

República de Colombia. Ley 114 de 1934.

República de Colombia. Ley 10 de 1934.

República de Colombia. Decreto 2350 de 1944.

República de Colombia. Ley 6ta de 1945.

República de Colombia. Decreto ley 1600 de 1945.

República de Colombia. Ley 90 de 1946.

República de Colombia. Ley 4ta de 1966.

República de Colombia. Decreto 3135 de 1968.

República de Colombia. Decreto ley 3135 de 1985.

República de Colombia. Ley 33 de 1985.

República de Colombia. Acuerdo 049 de 1990.

República de Colombia. Decreto reglamentario 1849 de 1969.

República de Colombia. Ley 100 de 1993.

República de Colombia. Ley 797 de 2003.

República de Colombia. Ley 860 de 2003. 